\title{
O PAPEL DA ATIVIDADE DISCURSIVA NO EXERCÍCIO DO CONTROLE SOCIAL
}

\section{Luiz Antônio Marcuschi}

\section{Abstract}

This article proposes that genres function as an integral part of socially organized activities and lend themselves to various types of social control, including the exercise of power. However, if the control exercised by genres is inevitable, it is not deterministic, since genres are historical, cultural and situated. Therefore, there remains space both for genre creativity and change as entities that are malleable, flexible and fit for discursive activity in daily life.

Key words: Genres; social control; discursive activity.

\section{Ponto de partida e pano de fundo}

O título deste artigo, originalmente uma conferência ${ }^{1}$, pode iludir os leitores num primeiro momento, mas aqui serão tratados aspectos relativos à vida (produção, circulação e funcionamento) dos gêneros textuais como formas de controle social. Não se trata de uma teoria dos gêneros e sim de uma tentativa de observação das conseqüências de uma determinada visão dos gêneros no âmbito das práticas discursivas. É uma análise de aspectos da interação entre gênero, discurso, estrutura social e relações de poder. O limite de tempo a que o gênero conferência (no presente caso, o limite de espaço do gênero artigo científico) está submetido exige concentração, cortes e não permite exaustividade. Essa é a inevitável frustração

1 Este trabalho foi produzido no contexto do Projeto Integrado "Fala e Escrita: Características e Usos", apoiado pelo CNPq, processo n ${ }^{\circ}$ 523612/96-6, e desenvolvido no Núcleo de Estudos Lingüísticos da Fala e Escrita (NELFE), Depto. de Letras da UFPE. Apresentado na forma de conferência na $55^{\mathrm{a}}$ Reunião Anual da SBPC na seção da ABRALIN- Recife, 13 a 18 de julho de 2003 . 
diante de conferências e artigos que, como gêneros textuais, são muito mais um filtro controlador de temas do que uma distribuição generosa do conhecimento. Tome-se isto como exemplo prático para esta reflexão, ou seja, o próprio gênero aqui praticado é uma espécie de controle. Depois de ouvir uma conferência, cada qual pode engatar nela outros gêneros, tais como uma crítica, um debate, um artigo científico etc., dando conta de outros aspectos, assumindo o controle e até mesmo oferecendo uma crítica. Eu mesmo engato na conferência original um gênero que dela decorre: um artigo científico.

Dois aspectos deveriam ficar claros nesta exposição: primeiro, os gêneros surgem e operam em nossas sociedades como formas de controle social, político, ideológico etc.; segundo, os gêneros constituem sistemas relacionados de enunciados e não agem isoladamente, em especial quando fazem parte do mesmo domínio discursivo, isto é, da mesma esfera de atividades humanas, como notou Bakhtin ([1953]1979). Em suma, enquanto atividades discursivas, os gêneros são efetivamente sistemas de controle resultantes de desenvolvimentos históricos, culturais, políticos e sociais.

\section{Teses Centrais}

Pretendo mostrar que os gêneros são atividades discursivas socialmente estabilizadas que se prestam aos mais variados tipos de controle social e até mesmo ao exercício de poder. Numa formulação sucinta, diria que os gêneros textuais são a nossa forma de inserção, ação e controle social. Toda e qualquer atividade discursiva se dá em algum gênero que não é decidido ad hoc, como já lembrava Bakhtin ([1953]1979) em seu influente ensaio sobre os gêneros do discurso. Daí também a imensa pluralidade de gêneros e seu caráter essencialmente sócio-histórico. Apontando a necessidade dos gêneros para a atividade discursiva, Bakhtin dizia que "se não existissem os gêneros do discurso e se não os dominássemos, se tivéssemos de construir cada um dos nossos enunciados, a comunicação verbal seria quase impossível" (Bakhtin, [1953]1979: 302). Portanto, além de tudo, os gêneros são também necessários para a interlocução humana. Tal como lembra Bazerman (1994: 1) 
"dependemos implicitamente de gênero na nossa invocação dos procedimentos interpretativos e avaliativos que consideramos apropriados a cada texto". Portanto, os gêneros realizam algo mais do que sua "tipicidade"; eles também nos guiam e até nos restringem, mas ao mesmo tempo nos motivam a "rebeldias' para "realinhamentos sócio-políticos".

Um simples exemplo pode dar a dimensão do que estou propondo. Tomemos a atividade discursiva na vida acadêmica e vejamos quem controla a cientificidade em nosso trabalho investigativo diário. Em boa medida, os gêneros por nós produzidos dão, pelo menos em uma primeira instância, legitimidade ao nosso discurso. Neste particular, certos gêneros tais como os ensaios, as teses de doutorado, os artigos científicos, os resumos, as conferências, aulas expositivas etc., assumem um grande prestígio a ponto de legitimarem e até imporem uma determinada forma de fazer ciência e decidir o que é científico. Há gêneros, tais como os pareceres produzidos pelos pares, que são tipicamente controladores e legitimadores da cientificidade. E com isso chega-se inclusive à idéia de que não são científicos os discursos produzidos fora de certos procedimentos canônicos na área acadêmica. ${ }^{2}$ Contudo, isso não forma uma taxonomia de poder normativo quanto à forma, pois esta pode ser constantemente burlada e inovada.

Com este pano de fundo em mente, parto de um pressuposto básico que poderia ser assim formulado: o controle social exercido pelos gêneros textuais é incontornável, mas não determinista. Por um lado, a romântica idéia de que somos livres e de que temos em nossas mãos todo o sistema decisório é uma quimera, já que estamos imersos numa sociedade que nos molda sob vários aspectos e nos induz a determinadas ações. Por outro lado, essas forças não são compulsórias e os gêneros textuais não criam

\footnotetext{
2 Observe-se que o mesmo trabalho de investigação quando publicado num jornal como, por exemplo, o DIÁRIO DE PERNAMBUCO, e depois, republicado numa revista de reputação científica como a DELTA, certamente terá avaliação diversa pelos pares. Isso ocorre com quase toda a produção científica. $\mathrm{O}$ suporte tem uma influência que exorbita o próprio conteúdo. $\mathrm{O}$ mesmo ocorre com um artigo publicado numa revista internacional em relação a uma revista regional de pouca circulação, ou numa língua de grande prestígio ou sem prestígio na academia. Portanto, há algo mais que gênero em questão.
} 
relações deterministas nem as perpetuam. Eles apenas as manifestam em certas condições de realização. Desde que nos constituímos como seres sociais, nos achamos envolvidos numa máquina sócio-discursiva. E um dos instrumentos mais poderosos dessa máquina são os gêneros textuais, sendo que de seu domínio e manipulação depende boa parte da forma de nossa inserção social e nosso poder social. Enfim: quem pode expedir um diploma, uma carteira de identidade, um alvará de soltura, uma certidão de casamento, um porte de arma, escrever uma reportagem jornalística, uma tese de doutorado, fazer uma conferência, uma aula expositiva, realizar um inquérito judicial, decretar uma lei e assim por diante?

É sabido que as atividades comunicativas são uma das formas de organização da sociedade e condicionam boa parte das demais ações praticadas em sociedade. De um modo geral, a maioria de nossas ações diárias são discursivamente estruturadas, tal como lembram Bergmann \& Luckmann (1995: 297), para quem um dos traços freqüentes nos gêneros é "um estoque comum de conhecimentos diários sobre normatividade e reputação social da atividade comunicativa prescritos e moldados pelos gêneros”. Isto faz com que tenhamos uma noção clara do que convém ou não convém em determinados momentos. Neste sentido, os gêneros estão muitas vezes "imbuídos de valores" e "são muito mais do que guias neutros para a realização de certas atividades comunicativas” (p. 297). Esses valores são também sistemas de coerção social.

A questão diz respeito igualmente à distribuição dos gêneros na sociedade. Tal como frisava Bakhtin ([1953]1979), os gêneros são apreendidos no curso de nossas vidas como membros de alguma comunidade. Neste caso, são padrões comunicativos socialmente utilizados, que funcionam como uma espécie de modelo comunicativo global que representa um conhecimento social situado. Sociedades tipicamente orais desenvolvem certos gêneros que se perdem em outras tipicamente escritas e penetradas pelo desenvolvimento tecnológico. É assim que em centros urbanos sofisticados são quase desconhecidos gêneros como os cantos de guerra indígenas, os cantos medicinais de pagés ou as benzeções de rezadeiras e os lamentos de carpideiras. Tais gêneros surgem e se desenvolvem naquelas sociedades como práticas culturais rotineiras como 
o editorial de um jornal diário, uma bula de remédio ou um blog para os adolescentes de classe média em nossas culturas. Os gêneros existem como formas estruturadoras de ações em todas as sociedades, mesmo as ágrafas. Veja-se a este propósito o estudo de Carol Feldman (1995) sobre os gêneros textuais orais entre os Ilongot nas Filipinas. A autora mostrou que esse povo tinha 13 gêneros textuais orais muito diversos entre si, com padrões organizacionais, estilos e linguagem próprios, que ela denominou "gêneros artísticos orais" (1995:56). Serviam inclusive para identificar papéis sociais dentro da comunidade. Muitas dessas formas genéricas não eram usadas no dia-a-dia das pessoas, pois tinham momentos especiais e ritualizados para suas práticas.

Assim, parece possível defender que a produção discursiva é um tipo de ação que transcende o aspecto meramente comunicativo e informacional. Daí não se poder considerar a atividade informacional como a função mais importante da língua. Eu me atreveria a dizer que a informação é um fenômeno eventual e talvez um simples efeito colateral no funcionamento da língua. Todos nós sabemos que a língua não é apenas um sistema de comunicação nem um simples sistema simbólico para expressar idéias. Mas muito mais uma forma de vida e uma forma de ação, como dizia o segundo Wittgenstein. E como as atividades discursivas estão organizadas em gêneros, esses são as verdadeiras formas de vida. Eu diria, numa metáfora um tanto desajeitada, que a língua não é uma estalagem e sim um estaleiro, isto é, nela não se dorme, nela se montam, constroem e lançam mundos ao mundo.

Com isto, pretendo defender a tese de que boa parte de nossas atividades discursivas servem para atividades de controle social e cognitivo. Quando queremos exercer qualquer tipo de poder ou de influência recorremos a atividades discursivas específicas. Ninguém fala só para exercitar as próprias cordas vocais ou os tímpanos alheios. Na realidade, o meio em que o ser humano vive e no qual ele se acha imerso é muito maior que seu ambiente físico e contorno imediato, já que está envolto também por sua história e pela sociedade que criou e pelos seus discursos. A vivência cultural humana está sempre envolta em linguagem e todos os nossos textos situam-se nessas vivências estabilizadas em gêneros, mas 
esta "estabilidade" é "relativa", como bem postulou Bakhtin ([1953] 1979), isto é, histórica e mutável ao longo do tempo.

Neste contexto, é central a idéia de que a língua é uma atividade sócio-interativa de caráter cognitivo, sistemática e instauradora de ordens diversas na sociedade. $\mathrm{O}$ funcionamento de uma língua no dia-a-dia é mais do que tudo um processo de integração social. Claro que não é a língua que discrimina ou que age, mas nós que com ela agimos e produzimos sentidos e assim por diante. Eu não gostaria de naturalizar a língua, pois isto seria pernicioso para a reflexão crítica que pretendo fazer aqui e redutor para a criação de um ponto de vista mais abrangente.

Partindo destes princípios gerais, analiso aqui um tema que me vem preocupando no estudo dos gêneros textuais, isto é, o seu caráter de instrumento social. Mesmo não me considerando um frankfurtiano, creio que podemos admitir que a instrumentalização da razão ou de qualquer outra coisa nesta área é sempre perniciosa. Por isso, não se pense que vou pleitear uma instrumentalização dos gêneros para a ação social. A pretensão é sugerir linhas de reflexão para se ver os aspectos sociais, históricos, cognitivos e o extraordinário potencial que os gêneros textuais têm como instrumentos de controle social ligado a instituições. Adoto a perspectiva da Análise do Discurso Crítica desenvolvida por Norman Fairclough (2001) alicerçado ainda em autores tais como Bakhtin ([1979]1979), Van Dijk (2001) e Carolyn Miller (1984) entre outros.

\section{OS GÊNEROS TEXTUAIS}

Antes de prosseguir, gostaria de esclarecer brevemente algumas noções. A primeira delas é a noção de discurso. Esta é reconhecidamente uma noção ambígua e tem variadas acepções. Discurso não será aqui entendido na acepção da ADF, isto é, como uma "dispersão de textos numa dada conjuntura", e sim segundo definido por Fairclough (2001: 90-91), como "uma forma de prática social e não como atividade puramente individual ou reflexo de variáveis institucionais". Esta visão "implica ser o discurso um modo de ação, uma forma em que as pessoas podem agir sobre o mundo e especialmente sobre os 
outros, como também um modo de representação" e implica ainda "uma relação dialética entre discurso e estrutura social" em especial "entre a prática social e a estrutura social"; implica também que "o discurso é moldado e restringido pela estrutura social'. Enquanto atividade constitutiva, o discurso contribui para:

1) a construção das identidades sociais;

2) a construção das relações sociais entre as pessoas;

3) a construção de sistemas de conhecimento e crenças.

Portanto, mais do que uma simples representação do mundo, o discurso é uma prática que constitui o mundo e produz efeitos de sentido (Fairclough, 2001: 91). Tanto atua na constituição e reprodução dessas identidades como também na sua transformação. Não se trata de uma determinação, mas de uma relação dialética. (p. 92). Não se deve, no entanto, exagerar a idéia de ser o discurso a origem do social, pois seus efeitos conjugam-se a outras práticas.

Situando estas questões no contexto de nosso tema, podemos, com Fairclough (2001:95), dizer que não são, portanto, os gêneros textuais particulares que têm valores políticos e ideológicos inerentes, e sim seu "investimento" de forma particular em domínios discursivos e instituições é que tem um valor político e ideológico, sendo capaz de se tornar num fator de controle social. Clifford Geertz (2000: 33-34) mostra, em primorosa análise sobre a "mistura de gêneros", que as mudanças culturais estão nos conduzindo a uma "reconfiguração do pensamento social" (p. 33) pela alteração dos gêneros. Assim, por exemplo, ensaios filosóficos parecem críticas literárias (Sartre sobre Flaubert); fantasias barrocas apresentam-se como observações empíricas (Borges); parábolas são tratadas como descrições etnográficas (Castañeda); estudos epistemológicos são produzidos como tratados políticos (Feyerabend) e assim por diante (pp. 33-34). Para Geertz, este fenômeno é muito mais generalizado e antigo do que podemos imaginar e vai além de uma simples revisão do mapa cultural, pois é efetivamente "uma mudança no próprio sistema de mapear" (2000:34). Se os gêneros podem ser tidos como poderosos sistemas de mapeamento, eles ajudam a constituir a própria visão dos fenômenos e até o nosso fazer científico. 
Para melhor acompanhar a argumentação geral, devemos esclarecer as duas noções a serem aqui utilizadas, isto é: tipo textual (ou de discurso) e gênero textual ${ }^{3}$.

1. Tipo textual (ou tipo de discurso) é uma seqüenciação textual definida pela natureza lingüística de sua composição \{aspectos lexicais, sintáticos, tempos verbais, relações lógicas, estilo\} e funcionalidade retórica; caracteriza-se mais como uma seqüência do que como texto materializado. Em geral, os tipos abrangem meia dúzia de categorias conhecidas como: narrativo, argumentativo, expositivo, descritivo, injuntivo. Quando predomina uma característica tipológica num dado texto concreto dizemos que esse é um texto ou argumentativo ou narrativo ou expositivo ou descritivo ou injuntivo, mas em geral os textos são tipologicamente heterogêneos.

2. Gênero textual refere formas textuais "relativamente estabilizadas" (Bakhtin) em situações comunicativas recorrentes. Os gêneros são os textos que encontramos em nossa vida diária e que apresentam padrões sócio-comunicativos caracterizados pela composição funcional, objetivo enunciativo e estilo realizados na integração de forças históricas, sociais e institucionais. Os gêneros se expressam em designações diversas constituindo em princípio listagens abertas, por exemplo: telefonema, sermão, carta pessoal, romance, bilhete, reportagem, aula expositiva, reunião de condominio, notícia jornalística, horóscopo, receita culinária, bula de remédio, lista de compras, cardápio, resenha, piada, conversação, conferência etc.

Estas duas noções serão usadas de maneira sistemática na acepção aqui sugerida, sendo que no caso de tipo seria conveniente adotar a expressão tipo de discurso, já que não se trata de um texto e sim de uma seqüência discursiva, como bem observa Bronckart (1999). Além disso, as noções de tipo e gênero não constituem uma dicotomia, mas sim uma forma complementar de realizar discursos. Pois todo gênero se realiza num texto

\footnotetext{
${ }^{3}$ Maiores detalhes podem ser vistos em Luiz Antônio Marcuschi, 2003.
} 
e todo tipo se dá como sequiência dentro de um gênero.

Fairclough (2001: 161), seguindo a esteira de Bakhtin, também sugeriu uma definição de gênero perfeitamente compatível com a que acabo de enunciar, ou seja:

Eu vou usar o termo 'gênero' para um conjunto de convenções relativamente estável que é associado com, e parcialmente representa, um tipo de atividade socialmente aprovado, como a conversa informal, comprar produtos em uma loja, uma entrevista de emprego, um documentário de televisão, um poema ou um artigo científico.

Para o autor, um gênero implica formas particulares de texto e modos de produção, distribuição e consumo. Assim, a nomeação do gênero é uma designação para um conjunto de ações que se desenvolvem socialmente e são normalmente reconhecidas como tal tendo em vista seus propósitos e seu engajamento social. Os gêneros são plásticos e maleáveis e não podem ser identificados rigidamente com base em formas ou estruturas básicas. Em obra posterior, Fairclough (2003: 65), em capítulo especial sobre os "gêneros e estrutura genérica" assim se expressa:

Gêneros são especificamente aspectos discursivos de maneiras de agir e interagir no curso de eventos sociais; podemos dizer que (inter)agir não é propriamente discurso, mas é muitas vezes basicamente discurso. Assim, quando analisamos um texto ou interação em termos de gênero, indagamos como ele figura e na e contribui para a ação social e a interação em eventos sociais...

Na obra de 2003, o autor analisa os gêneros na relação com o neocapitalismo e suas práticas discursivas que se manifestam na transformação de gêneros. Pois, para Fairclough (2003: 66), "a mudança de gênero é uma parte importante das transformações do neocapitalismo". Essas mudanças são novos arranjos dos gêneros para as novas funções.

Na verdade, devo fazer aqui uma ressalva importante. Pois não obstante a suposição de compatibilidade de minha posição com Fairclough (2001) acima afirmada, há problemas com este aspecto, pois Fairclough 
(2003: 68), ao analisar a questão da definição de gênero, aponta para a dificuldade com esse conceito pelos "diferentes níveis de abstração" a que essa noção está sujeita. Para o autor, se dissermos que uma Narrativa é um gênero, a reportagem e a notícia televisiva etc. seriam narrativas ou seriam gêneros a parte? O certo é que se tomarmos Narrativa, Argumento, Descrição etc. como gêneros, isso se daria num alto grau de abstração e não se vincularia a práticas sociais particulares como os gêneros do tipo notícia, reportagem, conferência, artigo científico. De resto, há ainda gêneros que pairam num nível de abstração um pouco mais baixo do apontado, mas não são situados, como a entrevista ou a carta, que admitem uma série de gêneros situados, como a entrevista jornalística, a entrevista de emprego, a carta comercial, a carta pessoal, entre outras. Diante disso, Fairclough (2003:69) sugere adotar três noções: (a) a noção de 'pré-gênero'para o caso de níveis mais abstratos como “Narrativa'; (b) a noção de 'gênero desencaixado' (disembedded genre) para o caso de designações de constelações, ou colônias de gêneros como 'entrevista' e (c) a noção de 'gênero situado' para os gêneros tais como 'entrevista etnográfica', 'carta pessoal' e assim por diante. Dificuldade adicional seria a questão dos gêneros mistos ou híbridos surgidos na relação de intergênero, tal como defini em Marcuschi (2001), por exemplo, uma publicidade no formato de uma carta pessoal. Isto significa que uma forma particular de texto nem sempre é em si um gênero determinado. Assim, não haveria uma correspondência biunívoca entre um gênero textual situado e uma forma textual concretamente realizada (v. Fairclough, 2003: 69). ${ }^{4}$

Estas questões contribuem para o grande problema de qualquer classificação, designação ou identificação dos gêneros. Isso reside em parte no fato de os gêneros serem plásticos e fluidos, interligados e muitas vezes híbridos, além de nossa maneira de lidar com textos concretos que temos pela frente. Por disso, será sempre difícil a formulação explícita dos critérios para essas categorizações. Por exemplo, uma maneira de identificar um gênero e

\footnotetext{
${ }^{4}$ Para Fairclough (2003: 69), aí reside uma das razões de sua discordância com Swales (1990) quando este "define gênero como "uma classe de eventos comunicativos". Segundo Fairclough (p. 69), “eventos atuais (textos, interações) não estão 'num' gênero particular, eles não instanciam um gênero particular”. Os gêneros emergem de forma criativa nos textos em situações concretas e particulares na atividade social.
} 
distingui-lo de outro seria determinar parâmetros com critérios do tipo:

- formato (características composicionais)

- natureza do tema

- propósitos ou objetivos

- tipo de ações envolvidas

- estrutura da participação

- situacionalidade

- inserção cultural

- domínio discursivo

- domínio institucional

Como se nota, esses não são critérios lingüísticos ou estruturais, mas sócio-comunicativos, que operam na identificação dos gêneros. Isto é algo operacionalmente tão complexo como pouco produtivo. Pois estas noções não são consensuais e se definem por critérios que se imbricam, provocando uma infinita série de caminhos e entrando num perigoso círculo vicioso. Daí a plausibilidade da posição de Bazerman (1994) quando afirma:

os gêneros são o que as pessoas reconhecem como gêneros em qualquer momento do tempo. Podem reconhecer os gêneros por nomeação, institucionalização e regularização explícitas, através de várias formas de sanção social e de recompensa.

Sanção social e recompensa são dois aspectos que mostram como os gêneros são socialmente legitimados e não como simples cumprimento de normas textuais. Em suma, podemos dizer que os gêneros são uma forma altamente elaborada de consciência sócio-cultural prática. Assim, para nossos objetivos imediatos, consideramos o gênero como uma atividade social particular e um funcionamento da língua em ações discursivas fixadas em textos, mas não num formato específico e fixo de texto. A rigor, o gênero é necessário e pode-se dizer, segundo bem observou Bakhtin:

...gêneros do discurso nos são dados quase como nos é dada a língua materna, que dominamos com facilidade antes mesmo que lhe estudemos a gramática. ... Aprender a falar é aprender a estruturar enunciados. ... Os gêneros do discurso organizam nossa fala da mesma maneira que 
a organizam as formas gramaticais. ... Se não existissem os gêneros do discurso e se não os dominássemos, se tivéssemos de construir cada um de nossos enunciados, a comunicação verbal seria quase impossível. ([1953] 1979: 301-2)

Isto leva-nos a admitir que os gêneros não são criados a cada vez pelos falantes, mas são transmitidos sócio-historicamente. Contudo, os falantes contribuem de forma dinâmica tanto para a preservação como para a permanente mudança e renovação dos gêneros, já que lhes cabe a missão de usá-los e dar-lhes a plenitude sentido. Fiel à sua postura teórica sobre a língua vista como atividade sócio-interacional e não como forma abstrata, Bakhtin admite como central na sua teoria dos gêneros o seu uso criativo. Mas é bom ter em mente que criatividade aqui nada tem a ver com ações individuais, voluntaristas e personalistas, ao modo de uma pragmática gricena, mas com usos inovadores decorrentes e ligados aos movimentos históricos.

Com base em Freedman \& Peter Medway (1994: 1), podemos afirmar que, sem abandonar concepções anteriores de gêneros como 'tipos' ou 'espécies' de discursos, caracterizadas por similaridades no conteúdo e na forma, as análises recentes enfocam a vinculação dessas regularidades lingüísticas e substantivas às regularidades nas esferas de atividades humanas.

Isto permite vincular de modo sistemático regularidades discursivas com regularidades sociais no funcionamento da língua e não simplesmente regularidades textuais. Assim, é interessante nos indagarmos: o que aprendemos quando aprendemos um gênero? Tudo indica que quando aprendemos um gênero não aprendemos uma forma lingüística mas, tal como sugere C. Miller (1984), aprendemos uma "forma de ação social”, ou se preferimos seguir Wittgenstein, aprendemos uma "forma de vida". É neste sentido que o estudo dos gêneros em sala de aula pode contribuir para uma "agenda social emancipatória”. E é por isso que vale a pena dedicar-se a uma análise do poder controlador dos gêneros textuais, pois eles são inalienáveis de toda nossa atividade discursiva, escrita ou oral.

A título de ilustração deste aspecto, cito aqui o caso trazido por Bazerman (1994) na nota dois de seu estudo. Depois de mostrar que os gêneros não são fixos, mas podem mudar e podem ser mudados por interesses políticos sinalizando novas ações discursivas, Bazerman narra-nos 
o que lhe comentou um colega a propósito deste tópico no contexto da revolução chinesa.

Gregory Gonsoulin me chamou a atenção para um caso interessante neste ponto - a rejeição explícita dos gêneros literários tradicionais chineses pelos reformadores culturais e políticos no início do século XX, conhecidos coletivamente como Movimento de 4 de Maio (denominados pela revolta de 1919), com a intenção de derrubar a tradição confuciana e promover a abertura para influências ocidentais. Os reformadores chineses perceberam os gêneros tradicionais como profundamente ligados à corte e às práticas educacionais que queriam derrubar. Eles alegaram, abertamente, a rejeição de gênero, mas implicitamente, moveram-se em direção à imitação dos gêneros ficcionais ocidentais, particularmente o da transformação russa, para refletir os novos valores e as novas relações sociais que esperavam estabelecer como parte de uma nova ordem política (Goldman, 1977).

Bazerman (1994) aponta outros casos em que os gêneros foram usados como estratégia de força política para táticas pouco recomendáveis para criação e manutenção de poder. Permito-me reproduzir mais um deles que foi examinado por William Hanks (1987), aqui reportado pela exposição de Bazerman (1994):

William Hanks (1987) examinou os gêneros de documentos coloniais pelos quais a sociedade maia foi trazida para o controle regularizado espanhol: cartas à corte, crônicas e a demarcação de terras. As representações que o povo maia conseguiu criar para si dentro desses documentos determinados pelos espanhóis formaram a identidade oficial dos maias, definindo suas relações com o governo espanhol. Através do tempo, essas representações oficiais estruturaram a ordem social naturalizada, um ambiente não-refletido para a vida diária.

Segundo Bazerman, nota-se neste relato "o poder prático dos gêneros particulares para expressar identidades e formar a base da vida diária”. Trata-se de um uso político dos gêneros poderosos que conseguem inclusive demarcar e forjar identidades culturais e sociais. $\mathrm{O}$ autor conclui sua observação afirmando que neste caso "vemos a maneira como os gêneros 
são realizados e transformados para fornecer um local para a negociação e luta política e econômica."

Muito comumente, a resposta à indagação de por que usamos um determinado gênero numa situação particular, tem sido dada em termos de situacionalidade e adequação dos participantes. Assim, diz-se que em uma situação particular requer-se um determinado tipo de ação que leva a um determinado formato textual ou exigência retórica. Do ponto de vista político e ético, uma tal maneira de ver o funcionamento retórico dos gêneros afigura-se neutra. Contudo, isso é uma ilusão e, tal como Fairclough (2001:96) lembra, a idéia de adequação é muito inadequada para explicar qualquer aspecto do funcionamento discursivo da língua. Para o autor, "contrariamente a abordagens baseadas em teorias da adequação, onde se supõe uma relação única e constante de complementaridade entre os elementos", melhor seria admitir "que a relação pode ser ou tornar-se contraditória". (p. 96)

Existem ali "linhas de tensão" em que os indivíduos se situam em diversas posições enunciativas. Um determinado discurso pode ser aceito em um ambiente e em outro não e sua aceitação não é um problema de adequação e sim de "formação de ordens discursivas". (p. 96) Veja-se a variação lingüística na escola, no trabalho, no lar e no lazer. Não é uma simples questão de estilo, mas de estilo expressivo. Ela é uma forma de controle e não se trata de um problema de adequação (p. 97). Estas tensões marcam limites e expansões de relações e regulam a ação lingüística como no caso de relações entre:

- pais e filhos

- pais e professores

- pais e vizinhos
X

$\mathrm{X}$

$\mathrm{X}$ filhos e professores ou filhos e vizinhos filhos...

Parece, portanto, que deve ocorrer uma mudança na reflexão a este respeito, indo-se da simples consideração das estratégias de produção para a consideração dos objetivos a que tais estratégias estão servindo. Opera-se um deslocamento do ponto de vista retórico ao ético e ao político. E com isto pode-se transformar os gêneros de instrumentos retóricos em instrumentos políticos na ação social. Não se trata propriamente do poder dos gêneros textuais, 
nem de sua cristalização em algum formato normativo cuja burla resulta em sanção, mas sim de seus investimentos em ordens discursivas diversas (p. 98). Pois os gêneros não são apenas artefatos ou objetos discursivos, mas também práticas sociais.

Resumidamente, pode-se dizer que Miller (1984), ao definir o gênero textual como uma forma de ação social, tornando-o assim dependente da estrutura e complexidade social de cada sociedade, relativizou o gênero, mas também deu-lhe uma nova consistência situando-o no âmago da realidade social. Aprender um gênero não equivale a aprender um conjunto de padrões formais para atingir determinados objetivos e sim aprender que objetivos podemos ter numa dada sociedade, ou seja, os gêneros são formas de inserção sócio-cultural (Miller, 1984: 38). Os gêneros, tal como a autora os compreende, são baseados em práticas retóricas e em convenções discursivas estabelecidas pela sociedade para a ação conjunta.

Uma década depois, Miller (1994: 71), em trabalho sobre o gênero como "artefato cultural", afirma:

O que eu quero propor, pois, é que se veja gênero como um constituinte específico e importante da sociedade, um aspecto maior de sua estrutura comunicativa, uma de suas estruturas de poder que as instituições controlam. Podemos entender gênero especificamente como aquele aspecto da comunicação situada que é capaz de reprodução que pode se manifestar em mais de uma situação e mais de um espaço-tempo concreto. (p. 71)

Podemos dizer que os gêneros ajudam a organizar o poder na sociedade. Os gêneros não são um reflexo da estrutura social, mas parte da própria estrutura e contribuem para a manutenção e para o surgimento de relações sociais e relações de poder social. Por que é que um burocrata qualquer ou um chefe de seção ou diretor de empresa, quando não quer atender alguém, pede para sua secretária informar que ele está em reunião? Porque todos sabem que uma reunião é algo ta solene e importante que não se interrompe. Imagine-se o poder que confere ao chefe o fato dele dirigir a reunião. Resumindo esta questão, diria que os gêneros podem ser vistos, entre outros aspectos, como: 
(a) formas relativamente estáveis de enunciados situados;

(b) modos de expressar intuitos (dizer intenções, realizar propósitos);

(c) originários de esferas da vida social (instituições, áreas do saber etc.);

(d) distribuídos pela fala e pela escrita;

(e) realizados com um plano de composição estilística;

(f) instrumentos auxiliares da compreensão;

(g) possuidores de um conteúdo temático;

(h) formas típicas de se dirigir a e construir um destinatário;

(i) modos de controle social do discurso;

(j) forças retóricas de grande efeito sócio-político.

Tendo este pano de fundo conceitual, podemos agora acrescentar mais um aspecto novo com alguns elementos da teoria da Análise de Discurso Crítica na visão de Fairclough (2001).

\section{A posição teórica de Norman Fairclough (2001)}

Sabidamente, Fairclough (2001) construiu uma teoria crítica do discurso que difere da Análise do Discurso Francesa em vários aspectos, mas em especial pela sua vinculação com o social e pela sua grande tendência a considerar os aspectos sócio-cognitivos do discurso. Além disso, trata-se de uma teoria altamente engajada no processo de transformação social pelo discurso e que tem atenção para os discursos do cotidiano e não apenas para os grandes discursos do arquivo da história. Não vou, no entanto, me dedicar a essa questão que pode ser vista na obra do próprio autor nos primeiros dois capítulos.

É oportuno ressaltar aqui que Fairclough tem posições relativamente novas em obras posteriores como em (2003) e outras. Mas as inovações são do ponto de vista da análise e da expansão dos conceitos que não são incompatíveis com os atuais. Assim, por achar que em 2001 o autor definiu com maior precisão a questão, detenho-me nesta obra. Segundo Fairclough (2001: 100), as práticas discursivas são moldadas de forma inconsciente pelas estruturas sociais, relações de poder e práticas sociais que vão ter influência direta nas relações sociais. Isto significa que não temos um controle direto e sempre imediato de nossos atos. 
Como frisado, neste momento, vou me concentrar especialmente no que Fairclough (2001) sugere sobre os gêneros textuais nos Capítulos 3 e 4 em que expõe seu modelo tridimensional do discurso (p. 101), representado na Figura 1:

\section{FIGURA 1: CONCEPÇÃO TRIDIMENSIONAL DO DISCURSO}

\section{PRÁTICA SOCIAL}

Constitui-se pelas relações de poder em que a HEGEMONIA tem papel central. Aqui entra a noção de IDEOLOGIA. A ideologia é propriedade dos eventos, atividades e estruturas e não propriamente dos textos já que eles são passíveis de vários efeitos e interpretações.

\section{PRÁTICA DISCURSIVA}

Produção, distribuição e consumo textual variando de acordo com as práticas sociais. Ex: os diversos gêneros são produzidos em circunstâncias específicas e particulares (teses, leis, conferências, depoimentos, contratos). Aqui a noção de GENERO TEXTUAL é básica.

\section{TEXTO}

Neste nível a análise volta-se para o vocabulário, a gramática, a coesão, a estrutura textual, os atos de fala, a coerência, a intertextualidade...

\section{PLANO DA DESCRIÇÃO}

PLANO DA PRODUÇÃO e PRÁTICA SOCIOCULTURAL

Fonte: N. FAIRCLOUGH. 2001, p. 101, com adaptações e acréscimos.

Para Fairclough (2001: 101-106), o texto tem muitos modos de organização e neste plano pode-se descrever o aspecto lingüístico de sua realização, bem como as questões mais especificamente pragmáticas. Trata-se do lugar das marcas enunciativas que podemos analisar com critérios e conceitos lingüísticos, pois afinal um texto é feito de língua. Volto a lembrar que para Fairclough (2003:69), "os gêneros associados com uma rede de práticas sociais constitui um potencial que é variavelmente configurado 
em textos atuais e interações”. Não há, pois, uma correlação direta entre textos concretos e gêneros no sentido que uma forma textual atualizada realiza sempre o mesmo gênero, pois isto depende de seu funcionamento concreto naquele contexto particular. Todos os gêneros realizam-se em textos, mas um dado texto nem sempre é um dado gênero de modo automático. Como não é este o nosso foco de atenção no momento, não me deterei neste ponto do modelo.

A prática discursiva (Fairclough 2001: 106-116) diz respeito ao aspecto aqui em foco e é o nível da interpretação textual, situando-se ali o gênero textual. Quanto a isso, o autor observa que "os textos são produzidos de formas particulares em contextos sociais específicos” (p. 107). Um artigo de jornal, por exemplo, é produzido numa série de ações coletivas e será consumido por sua circulação em variados contextos sociais. Mas ele sempre será fruto de uma dada visão do articulista situado no contexto de seu órgão jornalístico. Assim, não é indiferente ser jornalista da Folha de São Paulo ou do jornal $O$ Globo. Sempre existem instituições responsáveis pela produção textual e é uma ilusão imaginar que tudo fica por conta do jornalista enquanto indivíduo. Isso ocorre com todos os gêneros que por sua vez têm propósitos específicos. Vejamos alguns exemplos: (a) um romance e um poema têm um papel estético diferente do que um anúncio fúnebre ou uma receita culinária. Serão produzidos, recebidos e interpretados em condições totalmente diversas; (b) um tratado de Química e uma notícia de jornal recebem um tratamento interpretativo diverso e circulam em condições bem diferenciadas e para fins sociais diversos.

Como práticas discursivas, os gêneros textuais conduzem a ações textuais diversas. Veja-se o que é que esses gêneros controlam em termos de ações sociais típicas:

- certidão de casamento

- certidão de óbito

- alvará de soltura de preso

- cheque bancário

- diploma de doutor

- carta de recomen-

dação

- curriculum vitae

- projeto de douto-

rado

- ofício de nomeação

- editorial de jornal 
E assim por diante. Veja-se quem está autorizado a produzir cada um desses gêneros e o que cada um deles controla na vida social. Observe-se, também, onde eles circulam e como circulam. Eles têm dimensões sócio-cognitivas muito específicas tanto no seu processo de produção como de recepção e interpretação. Isto torna os gêneros uma espécie de modelos sócio-cognitivos de ação. Também podemos dizer que o poder social se dá em boa medida pelo acesso e pela possibilidade de operar com gêneros na sociedade. Não é só a condição de produtor de gêneros, mas também a condição de 'consumidor' que conta.

A prática social diz respeito à ideologia, e ao processo de produção na perspectiva sócio-cultural. Pois “a prática social (política, ideológica etc.) é uma dimensão do evento discursivo, da mesma forma que o texto". Prática discursiva (PD) e prática social (PS) se imbricam e se distinguem de formas diversas. A PD é uma forma particular de PS.

Como exemplo de aplicação das categorias e dos mecanismos de gêneros aqui sugeridos, tomemos o caso de um editorial da Folha de São Paulo que tem por objetivo identificar o papel da linguagem no funcionamento de certas relações de poder na sociedade. Não nos detenhamos em detalhes ideológicos, nem em elementos meramente formais que dizem respeito ao problema da estrutura e organização textual, mas permaneçamos nos dois planos apontados por Fairclough, isto é, o plano da prática discursiva e da prática social, que apontam para a produção, circulação e interpretação.

\section{Exemplo (1)}

\section{FolHA opinião}

São Paulo, domingo, 29 de junho de 2003

\section{LÍNGUA E PODER}

"A terapia teve um efeito idiossincrático com prognóstico favorável em caso de pronta supressão". Essa frase, enigmática para os não-iniciados nas sendas médicas, não significa muito mais do que "o remédio teve efeito contrário, mas não causará problemas se for suspenso logo". 
Esse é um dos exemplos de jargão que consta da reportagem sobre linguagens técnicas publicada na semana passada no caderno Sinapse. O jargão é de fato inevitável, mas isso não significa que ele deva ser empregado em todas as ocasiões. Com efeito, toda profissão, do telemarketing à física de partículas, acaba por desenvolver um vocabulário específico, muitas vezes impenetrável para o leigo. Não apenas neologismos são criados como palavras comuns podem ter sua significação alterada.

Em alguns casos, trata-se de uma necessidade. O jargão, no mínimo, economiza palavras, concentrando carga informativa em termos específicos. Quando um médico fala em "miocardiopatia idiopática", ele está na verdade dizendo um pouco mais do que apenas "problemas cardíacos de causa ignorada". No subtexto, um outro médico compreenderá que o paciente sofre de moléstia cardíaca de origem desconhecida e para a qual já foram descartadas as causas que mais comumente provocam doenças do coração.

Em determinadas áreas científicas, os próprios objetos de estudo não passam de jargão. É o caso, por exemplo, da linguística, com seus morfemas, sintagmas e lexemas, e da física de partículas, com seus quarks, glúons e léptons. No limite, sem o jargão, os fenômenos estudados não podem nem ser enunciados.

Reconhecer a importância e a necessidade do jargão em certas situações não significa chancelar seu uso indiscriminado. Um médico ou um advogado que se dirijam a seus clientes em linguagem técnica incompreensível estão, na verdade, atendendo muito mal ao consumidor, que deve ter, em todas as ocasiões, acesso a uma explicação completa de sua situação em linguagem acessível.

Infelizmente, as coisas nem sempre se passam assim. Desde que o mundo é mundo, profissionais de uma determinada área tendem a unir-se para manter sua arte impenetrável para o público em geral e, assim, aumentar seu poder. Não foi por outra razão que os escribas do antigo Egito complicaram desnecessariamente a escrita hieroglífica: era uma forma de conservarem e até de ampliarem sua posição hierárquica. Os tempos e as ciências mudaram, mas o princípio de complicar para valorizar-se permanece em vigor.

Não devemos, é claro, ser ingênuos e acreditar que poderemos promover a plena igualdade através da língua. Democracia é, antes de mais nada, a arte de negociar, de aplicar o bom senso na solução de problemas. Nesse sentido, o bom profissional é aquele capaz de comunicar-se no melhor jargão com seus colegas, mas que consegue, sem grandes perdas, fazer-se entender pelo leigo. Os que ostensivamente abusam da linguagem técnica tendem a ser os menos capazes, os que mais precisam afirmar-se para não perder poder.

A análise deste e outros textos deveria levar em conta as distinções feitas por Fairclough (2001:159-161) entre gênero, tipo de atividade, estilo e 
discurso, ao tratar da interdiscursividade. Estas noções e a idéia de texto aqui expostas podem ser usadas para constatar que o editorial que acabamos de ler é um gênero poderoso e que emite a opinião do jornal e não de uma pessoa enquanto indivíduo. Aliás, quanto a isso, tudo indica que os indivíduos dentro de um órgão de imprensa raramente agem como atores individuais, pois em geral fazem parte de um sistema tático mais amplo. Além disso, o editorial é uma atividade crítica que se situa na defesa de determinados ideais ou princípios com um estilo formal que lhe dá maior credibilidade e de tipo discursivo predominantemente argumentativo, ou seja, em favor de alguma idéia-núcleo. Com base nisto e de maneira mais sistemática, pode-se dizer que o editorial da Folha de São Paulo:

(1) Foi produzido como uma atividade discursiva na identidade ideológica da Folha de São Paulo, presumivelmente progressista e de uma esquerda intelectualizada, que sempre se arvora em conhecedora do melhor caminho, muitas vezes com atitudes missionárias na tentativa de ditar normas. No caso, o jornal trata de um problema relevante que é a excessiva complexidade da linguagem técnica quando um profissional como o médico se dirige a um cliente. É provável que poucos órgãos de imprensa produzissem um editorial do mesmo modo, embora pudessem propor os mesmos princípios gerais a respeito da relação entre língua e poder. Seria impossível imaginar, por exemplo, o Jornal Popular escrevendo esse editorial. Os tablóides mais dedicados ao esporte e ao crime dificilmente teriam uma preocupação desse tipo. Na realidade, o jornal defende que linguagem é poder e não apenas instrumento de comunicação.

(2) Esse editorial apresenta, quanto às 4 categorias de Fairclough: - gênero: editorial, produzido na perspectiva ideológica de um determinado órgão de imprensa;

- estilo: escrita formal com marcas enunciativas de natureza retórica tipicamente argumentativa e com abundância de exemplos comprobatórios;

- registro: linguagem jornalística erudita e voltada para intelec- 
tuais e fazendo uso de uma seleção léxica que de algum modo seleciona os leitores;

- discurso: do domínio jornalístico atuando em defesa do cidadão comum com algumas características técnicas.

(3) Foi produzido com escolhas lexicais e estruturas sintáticas de tal modo organizadas que monitoram, isto é, identificam com grande precisão seus interlocutores definidos já pelas normas de redação do próprio órgão. Os leitores da Folha de São Paulo são precisamente aqueles que estão aptos a entenderem a linguagem que o jornal critica.

(4) Tem um alto grau de autocontradição ao lidar com o problema da linguagem e poder mostrando como essa linguagem é segregadora e ao mesmo tempo ele próprio, como editorial, é segregador e se dirige preferencialmente a um público que entende a Folha de São Paulo.

Em suma, esse editorial vem associado a um estilo particular, na modalidade escrita padrão, com um modo retórico argumentativo na esfera de atividades discursivas jornalísticas, voltado para seu público: um classe média esclarecida. $\mathrm{O}$ ethos jornalístico é o de quem fala como se fosse o porta-voz de uma grande massa de leitores e reproduz o aspecto ideológico inalienável da instituição.

É inegável que a ideologia se materializa nas práticas da instituição, interpelando os sujeitos e delimitando os espaços de luta (v. Fairclough, 2001: 116-120). Mas a ideologia não está no texto porque ele pode ter várias leituras e vários sentidos, embora todos compatíveis. Os sujeitos podem transcender as ideologias porque elas não vêm prontas no texto. Elas surgem ligadas a eventos e práticas bem como a estruturas de classe e gênero social, grupo, etnia etc.

Esse editorial pode muito bem figurar num livro didático para discutir a questão da 'relação linguagem e poder' esquecendo completamente que se trata de um editorial da Folha de S. Paulo. Isso seria secundário porque a escola pode neutralizar um gênero e tratar como se fosse apenas um texto com um discurso a ser produzido naquela circunstância. 
Portanto, mesmo um texto enquanto um gênero bem definido e marcado pode, em determinadas condições, ser neutralizado. $O$ gênero não é algo intrínseco à forma e sim a uma função dentro de um quadro de produção.

Aspecto interessante neste contexto é o que diz respeito ao ethos (Fairclough, 2001: 207-209) enquanto um processo de modelagem de identidades e que passa para o próprio gênero. Trata-se de um comportamento que visa à construção de identidades para o processo comunicativo. Esse ethos se manifesta socialmente, por exemplo, pela expressão corporal e pela forma de apresentação pessoal como nestes casos:

- ethos médico

- ethos do professor universitário

- ethos do operário de fábrica

- ethos do empresário

- ethos do cientista

- ethos do taxista

Eu posso me adaptar sem imitar, mas sendo solidário, amigo, bom ouvinte etc. $\mathrm{O}$ ethos constrói um conjunto de atitudes ordenadas pelas práticas do grupo e pode inclusive ser um fator de categorização social. Por exemplo, o médico ou o professor Universitário têm modos de perguntar, responder, tratar, vestir-se e assim por diante que os caracterizam e quando um deles foge ao padrão isso é notado. O ethos contribui para a construção do "eu social”, isto é, um eu discursivamente produzido na ação e que vai se manifestar no ato de produção de um gênero. $\mathrm{O}$ ethos é um estilo de comportamentos moldados por uma memória social que atua também na construção dos gêneros.

\section{Modos De CONTROle E SUAS CONSEQÜÊNCIAS}

A questão central aqui era: o que é e como se manifesta o controle social na atividade discursiva mediante os gêneros textuais? E agora podemos responder que o controle social se manifesta na atividade discursiva pela seleção de um gênero realizado num determinado estilo e com um ethos característico produzindo um discurso numa determinada esfera de atividade humana. 


\section{FIGURA 2: ALGUNS TIPOS DE CONTROLE EXERCIDOS PELOS GÊNEROS}

\begin{tabular}{|l|l|}
\hline \multicolumn{1}{|c|}{ Tipo de controle } & \multicolumn{1}{c|}{ Gênero } \\
\hline - controle de tópico & Entrevistas, aulas, inquéritos \\
\hline - controle de status & Saudação \\
\hline - controle de cientificidade & Artigos científicos, tratados, teses \\
\hline - controle de ação & Ordem de prisão, receita médica, \\
\hline - controle de direitos & Leis, regulamentos, patentes, registros \\
\hline - controle de crenças & Sermão, orações, catecismos \\
\hline - controle de ideologias & Manifestos, declarações \\
\hline
\end{tabular}

Neste ponto, podemos aceitar o que propõe G. Kress (1997: 22) quando lembra:

ao desnaturalizar as práticas discursivas como um conjunto de práticas de uma sociedade, entendida como um conjunto de comunidades ligadas discursivamente, e ao tornar visível e manifesto aquilo que antes pode ter sido invisível e aparentemente natural, os analistas críticos do discurso pretendem mostrar o modo como as práticas lingüístico-discursivas estão imbricadas com as estruturas sociopolíticas mais abrangentes de poder e dominação.

O lugar de onde eu falo é constitutivo do que eu digo e do poder do que eu digo. Isto é tão forte e tão verdadeiro que, no limite, funciona como forma de controle do discurso. E este lugar é em geral uma instituição ou uma posição dentro dela. Contudo, devemos ter claro que um gênero produzido nestas condições apenas delimita o conjunto de ações possíveis ou necessárias, mas ele não especifica, de modo que deixa aberta a porta à variação e criatividade.

Resumindo a posição até aqui exposta, pode-se dizer que as relações discursivas de dominação relacionam-se ao gênero de maneira bastante sistemática como observou Fairclough (2001). Escolher um gênero, produzir um gênero, ter acesso a um gênero num órgão de imprensa, por exemplo, é uma forma de exercer poder discursivo na sociedade. Van Dijk desenvolveu este 
aspecto ao analisar o acesso à imprensa por parte de camadas sociais desprivilegiadas, segregadas ou minoritárias. Entre nós, a Dissertação de Mestrado de Karina Falcone (2003) sobre "O acesso dos excluídos ao espaço discursivo do jornal”, mostra o desprivilegio dos excluídos socialmente no caso do Movimento dos Trabalhadores Sem Teto (MTST). Tratando de gêneros pouco poderosos, isto é, notícia, nota de opinião e entrevista ping-pong, a autora constata a ausência sistemática dos membros do MTST com poder informativo próprio. Portanto, nem todos têm o mesmo acesso a espaços públicos para exporem suas idéias e poucos podem produzir gêneros poderosos. Seguramente, os gêneros mais poderosos são produzidos pelas autoridades instituídas e não pelos líderes emergentes de movimentos sociais contestadores.

\section{ObSERVAÇÕES FINAIS}

Destas análises sumárias deve ressaltar a noção de que os gêneros são organizações textuais "relativamente estabilizadas" que funcionam como peças sociais e permitem monitoração social e controle sócio-cognitivo da ação discursiva com enorme potencial de dominação e poder. Eles têm influência direta e concreta sobre nossa vida diária. Mas o certo é que nem todos os indivíduos produzem toda espécie de gêneros textuais, pois esta é uma questão de inserção social e não de decisão individual. A própria sociedade se organiza em grandes núcleos produtivos que praticam atividades discursivas específicas. Valeria a pena levar adiante estas sugestões de trabalho e investigar detidamente as relações entre a prática discursiva e a prática social como formas de organização de nossa vida cotidiana através de gêneros. Pois parece correto afirmar que uma sociedade tem uma configuração particular de gêneros que por sua vez configuram um sistema que controla o funcionamento da sociedade como um todo e em aspectos particulares (v. Fairclough, 2001: 162). Basta ver que somos controlados por escrituras de apartamentos, casas e terrenos; tratados; leis; decretos; regulamentos; contratos; patentes; diplomas; editais; publicidades e uma infinidade de outros gêneros poderosos. Mas há ainda uma outra infinidade de gêneros que igualmente nos controlam, embora de maneira mais sutil, como editoriais; notícias; reportagens; contos; fábulas; fofocas e assim por diante. 
Por fim, tudo isso deveria funcionar também como um alerta para o trabalho escolar. Estou convencido de que a escola deveria trabalhar com uma boa variedade de gêneros, e em especial com aqueles de maior relevância na prática social, a fim de propiciar ao cidadão condições de atuar de forma mais eficiente nas operações discursivas na vida diária. Não se trata propriamente de ensinar a produzir gêneros, mas de ensinar a agir com eles, pois neste aprendizado reside a capacitação para uma prática que permitirá a sobrevivência digna do animal discursivo que somos.

\section{REFERÊNCIAS BIBIOGRÁFICAS}

Bakhtin, M. Estética da criação verbal. 3 ed. São Paulo: Martins Fontes, [1953] 1979.

Bakhtin, M. / Volochínov, V. N. Marxismo e filosofia da linguagem. 10 ed. São Paulo: Hucitec/Anna Blume, 1979.

Bazerman, C. Social forms as habitats for action. Version delivered at the 1994 Meeting of the Modern Language Association (mimeo), 1994. [Texto do mesmo autor, a ser publicado em 2005 na coletânea Gêneros textuais, tipificação e interação pela Cortez, em organização de A. P. Dionísio e J. Hoffnagel. A citação aqui feita é dessa tradução.]

Bergmann, J. \& Luckmann, T. Reconstructive genres of everyday communication. In: U. M. Quasthoff (Hrsg.) Aspects of oral communication, Berlin: Newmeyer, 1995, p. 289-304.

Bronckart, J.-P. Atividades de linguagem, textos e discursos. Por um interacionismo sócio-discursivo. São Paulo: Editora da PUC-SP, EDUC, 1999.

Fairclough, N. Analysing discourse. Textual analysis for social research. Londres e Nova York: Routledge, 2003.

---. Discurso e mudança social. Coord. trad., revisão e pref. à edição bras. I. Magalhães. Brasília: Editora Universidade de Brasília, 2001.

---. Discurso, mudança e hegemonia. In: E. R. Pedro (org.) Análise crítica do discurso. Uma perspectiva sociopolítica e funcional. Lisboa: Caminho, 1997, p. 77-103.

Falcone, K. O acesso dos excluídos ao espaço discursivo do jornal. Dissertação de Mestrado, PG em Letras, UFPE, Recife, mimeo, 2003. 
Feldman, C. F. Metalinguagem oral. In: D. R. Olson \& N. Torrance (orgs.). Cultura, escrita e oralidade. São Paulo: Ática, 1995, p. 54-74.

Freedman, A. \& Medway, P. (orgs.) Genre and the new rhetoric. Londres: Taylor \& Francis, 1994.

Geertz, C. O saber local: Novos ensaios em antropologia interpretativa. Petrópolis: Vozes, 2000.

Kress, G. Considerações de caráter cultural na descrição lingüística: para uma teoria social da linguagem. In: E. R. Pedro (org.) Análise crítica do discurso: Uma perspectiva sociopolítica e funcional. Lisboa: Caminho, 1997, p. 47-76.

Marcuschi, L. A. Gêneros textuais: definição e funcionalidade. In: A. P. Dionísio, A. R. Machado \& M. A. Bezerra (orgs) Gêneros textuais \& ensino. Rio de Janeiro: Lucerna, 2003, p. 19-36.

Miller, C. R. Genre as social action. In: A. Freedman \& P. Medway (orgs.). Genre and the new rhetoric. Londres: Taylor \& Francis, [1984] 1994, p. 23-42. (Reedição do original de 1984).

--- . Rhetorical community: The cultural basis of genre. In: A. Freedman, \& P. Medway, Genre and the new rhetoric. Londres: Taylor \& Fracis, 1994, p. 67-78.

Van Dijk, T. A. Opinions and ideologies in the press. In: A. Bell, P. Garrett (orgs.) Approaches to media discourse. Oxford: Blackwell, 1998, p. 21-63.

---.Discourse as interaction in society. In: T. A Van Dijk (org.). Discourse as social interaction. Londres: Sage, 1997a, p. 1-37.

---. Semântica do discurso e ideologia. In: E. R. Pedro (org.) Análise crítica do discurso. Uma perspectiva sociopolítica e funcional. Lisboa: Caminho, 1997b, p. 105-168.

Wittgenstein, L. Investigações filosóficas. São Paulo: Abril Cultural, [1953] 1975. (Coleção "Os Pensadores", Vol. XLVI). 